\title{
Antitheft Alarm System for Electric Motor Pumps
}

\author{
Pradnya Thorat ${ }^{1}$, Ravindra N. Rathod ${ }^{2}$ \\ Undergraduate Student, Government College of Engineering Karad, Satara, India ${ }^{1}$ \\ Assistant Professor, Government College of Engineering Karad, , Satara, India ${ }^{2}$
}

\begin{abstract}
An anti -theft system for electric motor includes controller, feedback circuit and alarm circuit. The feedback circuit continuously monitor the electric motor load, if the motor load is disconnected controller gives alarm with the help of buzzer This paper reports the design and development of an innovative anti -theft alarm system for electric motor pumps. The pumps are frequently stolen which as serious impact on agricultural production in accordance with the advantage of current transformer, MAX 485 Low power slew rate limited transceiver. The system consists of three main parts a PIC microcontroller, Current transformer and signal driver and feedback circuit. The Electric Motor costs are very high, when motors are on,it's very simple to detect the stealing of cables and motors when motors are off,it's very difficult to detect the stealing of the motors. The unit is part of motor driving circuit, cannot be identified easily as an anti-theft electric motor by the burglar
\end{abstract}

Keywords: Agriculture, alarm system, current transformer, PIC microcontroller, relay, pond, canal, electric water pump, nursery, intruder, yacht etc.

\section{INTRODUCTION}

Previously anti-theft devices are made to prevent theft of B. Objective and Scope of the system motor vehicle, boat and yacht, car, and truck etc. The objectives of this system are

Similarly, anti-theft systems are develop to prevent theft in 1 . To design and develop the system which detect the retail show room, library. An anti-theft device for electric stealing of the electric water pump motor

water pump motor includes current transformer which is 2 . To give the alarm when stealing of electric water pump widely used for metering and protecting relays. The motor has been detected

Electric water pump motors are installed for away on 3. To make a product design, which looks like an internal water well, water resources like rivers, canals, ponds - part or driving part of the electric water pump which is not standing water etc., and it is very difficult to monitor the easily identified by the intruder.

electric water motor as they are installed at far away The scope of the system

distance, their monitoring is difficult as motors are in off The anti - theft alarm can be implemented where the conditions, the thieves have good changes to steal these agricultural field, nursery for plant development, green electric water pumps as they are in off conditions, and in houses for vegetable production, water pumping stations remote areas, which cost very high, these electric water and agro - tourism,irrigation, fish-pond operation, pumps are chosen according to the need of water from 0.5 livestockwatering, building and houses with sufficient hp to $10 \mathrm{hp}$ which costs near about seven thousand rupees water supply etc.

to several thousand rupees, which will be great loss for the small scale farmers in terms of money as well as agricultural production loss. The anti-alarm system proposed in view of application in nursery, low cost green houses for vegetables production, Agro-tourism.

A. Selecting an anti-theft alarm system for electric water pump

There are several cases found for stealing of electric water pumps in rural India, where people are complaining about stealing of electric water pumps, and there is no remedy for this problem and hence there is demand from the farmers, When the electric water pumps are on,it's very simple to detect the stealing of cables and motors but it is very difficult to detect the stealing, when the electric pump are in off condition

\section{SYSTEM ARCHITECTURE}

Today theft of motor is great concern because of its high cost and reliability of farming on motor; it is also not affordable for farmers to buy new motors, this is the system which provides security and indication for the electric water pumps at a very low cost compared to the cost of electric motor being stolen the anti- theft alarm system cost nearly $5 \%$ of electric motor. This is system is suitable for detecting theft of electric water pump motor which are installed at remote location. There are so many applications where remote pumping is done with the help high cost electric motors such as irrigation, fish pond aeration, livestock watering, building and houses. This system has typical rural and remote application 
IARJSET

Vol. 4, Special Issue 2, January 2017

This anti-theft alarm system consists of these parts, A PIC Controller, current transformer, motor on/off detection andAlarm system

The system architecture of anti-alarm system as shown in fig 1 .

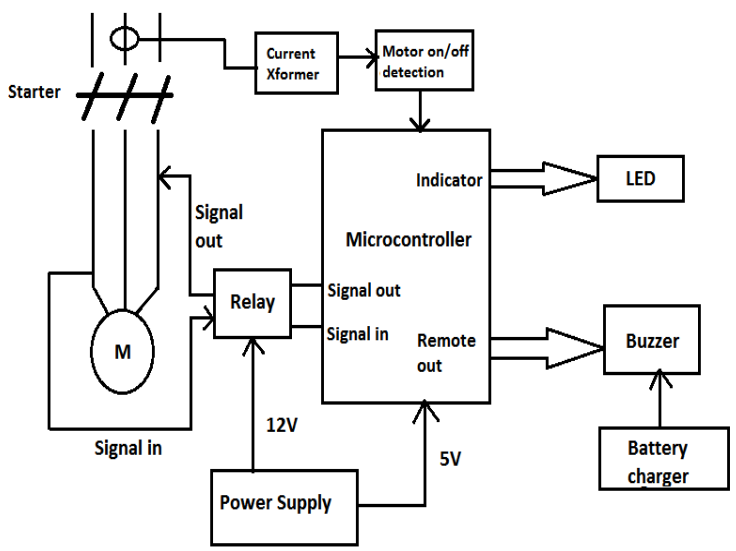

Fig 1: Architecture of anti -alarm System

\section{A. PIC16F1503 Microcontroller}

This is low cost and easily available microntroller which has 14pins, we do not need to connect multiple outputs and inputs, this has sufficient pins to connect input and output. it has $3.5 \mathrm{~kb}$ linear program memory and 128 bytes of linear data memory in this micron roller PORT A will configured as input port and PORT $\mathrm{C}$ will be configured as output port, signal in form the current transformer is connected to the one of the pin of port $\mathrm{A}$, and the alarm circuit is connected to the port C of PIC16F1502 Microntroller

\section{B. Current Transformer}

Current transformer is used in electronic equipment's and widely used for metering and protecting relays in the electrical power industry. The current transformer which have turns ratio $1000: 1$, it means the current on primary side is $30 \mathrm{~A}$ and that on the secondary side is $30 \mathrm{~mA}$.

\section{Motor on/off Detection}

The motor on/off detection circuit as shown in fig. 2 .

which consists of current transformer with turns ratio 1000:1 transforms 30A current into 30mA current, which continuously sense electric water pump is in the circuit or not gives input signal to microcontroller in the form of the voltage provided by divider network as shown in the circuit.

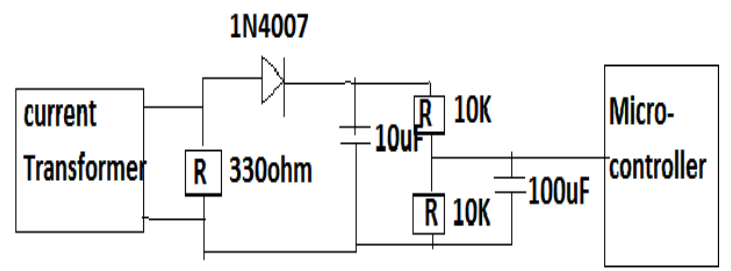

Fig .2 Motor on/off detection circuit
D. Signal driver and feedback circuit

The signal driver circuit consists of Two $12 \mathrm{~V}$ Relays in two PC817 opto coupler which isolates $12 \mathrm{~V}$ power from $5 \mathrm{~V}$ power supply the signal in and signal out signals are decided by PIC 16F1503 Microcontroller. The signal driver and feedback circuit is as shown in figure 3 .

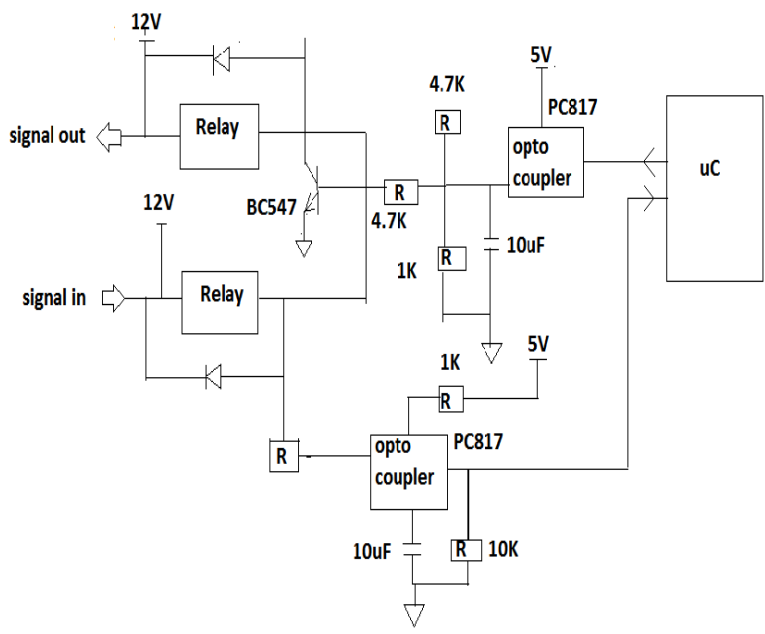

Fig.3. signal driver and feedback circuit

E. Alarm circuit

The alarm circuit consists of Two Max 485 which acts as transmitter and receiver, to the receiver side $12 \mathrm{~V}$ buzzer is connected, which will be continuously on when the Electric water pump will not in the circuit. To one of the Max485 Microntroller output pin is connected, which gives you the signal when the electric water pump not in the circuit as shown in fig .5. To the $12 \mathrm{~V}$ buzzer a $12 \mathrm{~V}$ dc adapter is connected,even though intruder cuts the power supply the external adaptor supplies the power to the buzzer.

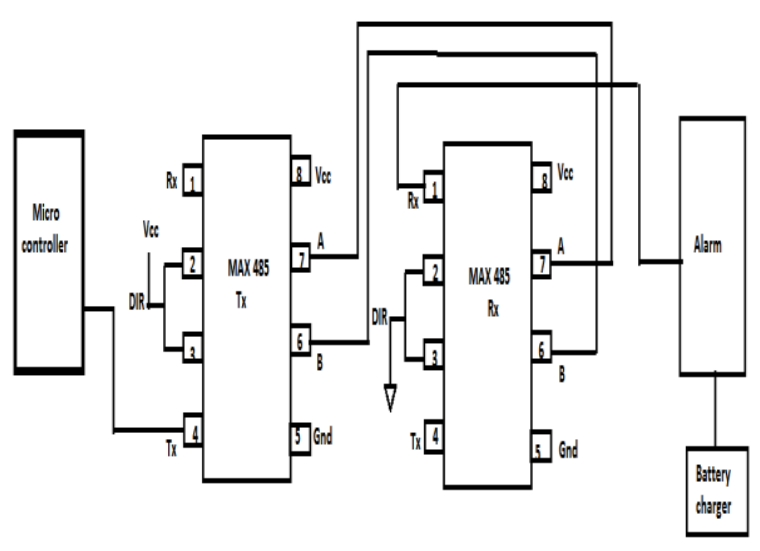

Fig 4. Alarm circuit

\section{III.RESULTS}

The system will automatically detect if motor is disconnected from the circuit and gives alarm. 
Vol. 4, Special Issue 2, January 2017

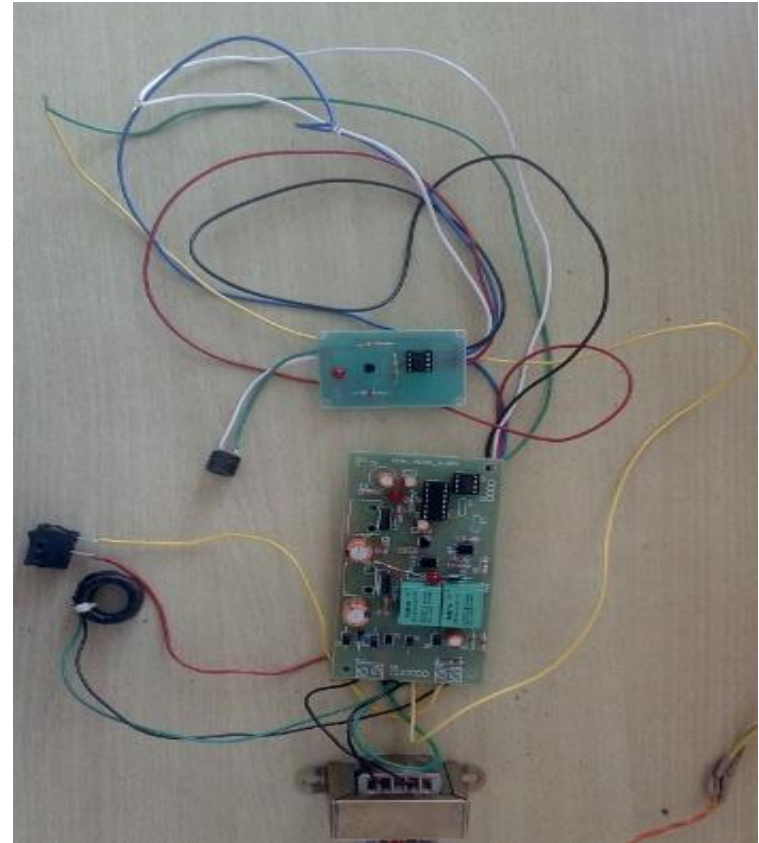

Fig. 5. Proposed anti-theft alarm system for electric water pump

\section{IV.CONCLUSION AND FUTURE SCOPE}

The system is low cost, efficient, low power consumption easy to use to protect the electric water pumps which are installed at remote location from theft. it also detects the functionality of the motor. The future scope of the system is including GPS system which will monitor the location of the motor, where two or more than two electric water pumps motors are used. The system can be developed to prevent dry run of the motor. The system can be controlled with the help of android application program.

\section{ACKNOWLEDGMENT}

We would like to express our gratitude towards Meghdoot Agro Industrial equipment, Sangli for their kind cooperation and encouragement which helped us in completion of this system

\section{REFERENCES}

[1] http://meghdootagro.com/.

[2] Somboom phonghphu and Panya Srichandr,Development of motor cycleAnti-theft alarm Singapore IPCSIT, 2011, vol. 7.

[3] Arthur D. Little, "A Vehicle Anti -theft security system design," Technical Report, U.S. Department of commerce vol. 2, PB-296 809

[4] Sagar Khole , Tushar Kolape , Mrs .A.P. More , "Automated Drinking water supply system and theft identification using Embedded Technology," in IJIRCCE , Vol 3, Issue 3, March 2015

[5] Juan Huan, Xingqiao Liu "A Burglar Alarm System Based in ZigBee and GSM for Aquaculture," Sensor and Transducers, Vol .175 , Issue 7, July 2014 ,pp.273-278

[6] M.V.N.R. Pavan Kumar "Water Anti-theft and Quality Monitoring System by using AVR and SCADA", IJRAT, vol.2, No.04, April 2014 E-ISSN:2321-9637
[7] Johanne Bacusmo ," Solar water pumping system", www.groundwaterinternational.com oct 2013

[8] U.S. Patent "Anti -theft device for motor vehicles", Patent number 5085061 date feb4,1992.

\section{BIOGRAPHY}

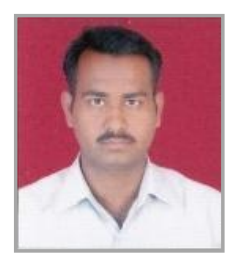

Ravindra N. Rathod was born in $14 / 06 / 1982$, he received is M. Tech degree from NIELIT, Aurangbad ,India in the field of Electronics Design and Technology , Currently he is working as an assistant professor in GCE , Karad .His research fields include electronic system design, control system and optimization, micro strip antennas 